\title{
PKM Pendampingan Strategi Pemasaran Berbasis Self-Organizing Maps untuk Meningkatkan Layanan Pelanggan di CV Karunia
}

Kamil Malik ${ }^{1}$, Istiqomatus Septiani ${ }^{2}$, Iva Nikmatul Maula ${ }^{3}$, Julita Maudi Riski ${ }^{4}$, Kholidatur Rosyida ${ }^{5}$, Kholifatus Sholeha ${ }^{6}$, Laily Musyarofah ${ }^{7}$, Nida Famutiyari ${ }^{8}$, Tahta Annisa ${ }^{9}$, Zulfa Lailatus Syarifah ${ }^{10}$

Universitas Nurul Jadid, Paiton ${ }^{1,2,3,4,5,6,7,8,9,10}$ nomor1001@gmail.com

\begin{tabular}{|c|c|}
\hline Submission: 3 & Published: 31/12/2021 \\
\hline $\begin{array}{l}\text { Katakunci: } \\
\text { Segmentasi } \\
\text { Pelanggan, } \\
\text { Metode SOM, } \\
\text { Strategi } \\
\text { Pemasaran, }\end{array}$ & $\begin{array}{l}\text { Abstrak. CV. Karunia merupakan salah satu distributor yang } \\
\text { bergerak di bidang penjualan dan distribusi kosmetik, salah satu } \\
\text { tugasnya adalah melayani pelanggan yang telah melakukan } \\
\text { pemesanan, oleh karena itu untuk setiap pengiriman pesanan } \\
\text { harus tercatat dengan baik. Agar distributor bisa mengelompokkan } \\
\text { pelanggan sesuai wilayah dan pesanan, cara ini memudahkan } \\
\text { untuk mengetahui wilayah mana dan pelanggan yang hanya } \\
\text { memiliki jumlah pesanan paling banyak. Oleh karena itu harus } \\
\text { mempunyai strategi pemasaran, misalnya dengan menggunakan } \\
\text { metode SOM (Self Organiz-ing Maps) yang bertujuan untuk } \\
\text { memudahkan upaya pemasaran dan pengelompokan pelanggan } \\
\text { sesuai dengan keinginan dan kebiasaan pelanggan, agar } \\
\text { memperoleh hasil yang maksimal. upaya pengambilan keputusan } \\
\text { pelanggan dan optimalisasi proses layanan pelanggan dan } \\
\text { optimasi. }\end{array}$ \\
\hline
\end{tabular}

\section{Pendahuluan}

Kesehatan reproduksi merupakan suatu kondisi atau keadaan sehat secara menyeluruh baik kesejahteraan fisik, mental dan sosial yang utuh dalam segala hal yang berkaitan dengan fungsi, peran dan proses reproduksi yang dimiliki oleh remaja (Bayang, 2016).

Dunia usaha memegang peranan penting dalam pembangunan, baik yang diusahakan oleh pemerintah melalui Badan Usaha Milik Negara (BUMN) maupun yang dilaksanakan oleh pihak swasta. Perusahaan yang sukses hanya mampu dicapai dengan manajemen yang baik, yaitu manajemen yang mampu mempertahankan kontinuitas perusahaan dengan memperoleh laba yang maksimal karena pada dasarnya tujuan perusahaan adalah memaksimalkan ke-makmuran perusahaan itu sendiri. Keberhasilan perusahaan dalam mempertahankan kontinuitas atau kelangsungan 
hidupnya bisa dicapai bila perusahaan tersebut memiliki pandangan ke luar dan selalu memonitor keadaan lingkungan yang berubah-ubah serta menyesuaikan usaha pemasarannya berdasarkan peluang-peluang yang dimiliki. Untuk mencapai kesuksesan tersebut, maka manajer sangat berperan dalam memilih dan merencanakan strategi pemasaran guna memenuhi kebutuhan konsumen. Saat mengembangkan strategi pemasaran, manajer harus mempertimbangkan untuk tidak hanya memenuhi kebutuhan konsumen, melainkan juga mempertimbangkan posisi industri perusahaan yang bersangkutan dibandingkan perusahaan pesaing. Oleh karena itu, manajer pemasaran harus merancang strategi pemasaran yang kompetitif dan sepadan dengan posisi dan sumber daya pesaing serta menyesuaikan strategi-strategi tersebut dengan kondisi persaingan secara berkesinambungan.

Suatu organisasi yang memutuskan untuk beroperasi di salah satu pasar konsumsi, mengakui bahwa pada dasarnya organisasi tersebut tidak dapat melayani semua pelanggan. Hal ini dikarenakan para pelanggan menuntut untuk dilayani secara efektif dan efisien sedngkan jumlah pelanggan terlalu besar, wilayahnya terlalu luas, beraneka ragam kebutuhan dan keinginan serta kebiasaan dalam membeli. Untuk itu, salah satu upaya yang dilakukan oleh perusahaan agar dapat tetap berada dalam posisi yang efektif dalam melayani segmen-segmen pelanggan yang memadai dari pasar yang dituju adalah dengan menetapkan segmentasi pelanggan. Segmentasi pelanggan pada dasarnya merupakan suatu cara untuk membedakan pelanggan menurut bebera-pa karakter dan tingkah laku. Menyadari pent-ingnya penerapan segmentasi pelanggan, maka obyek yang akan diteliti pada penelitian ini ada-lah CV. Karunia, yakni sebuah perusahaan yang bergerak pada bidang industri kosmetik, CV. Karunia dikenal sebagai salah satu produsen kosmetik besar di kawasan Kota Probolinggo.

Sebagai gambaran awal, berikut ini adalah perkembangan penjualan CV. Karunia dikawasan Kota Probolinggo untuk semua kosmetik dari tahun 2013 sampai dengan 2018: 
Tabel 1. Perkembangan Penjualan Kosmetik

di Kawasan Probolinggo pada CV. Karunia tahun 2013-2017

\begin{tabular}{|c|c|c|}
\hline Tahun & Unit Penjualan kosmetik & Perkembangan penjualan (\%) \\
\hline 2013 & 258.743 & \\
\hline 2014 & 281.771 & 8,9 \\
\hline 2015 & 280.736 & 8,5 \\
\hline 2016 & 283.841 & 9,7 \\
\hline 2017 & 287.722 & 11,2 \\
\hline Total & 1.392 .813 & 38,3 \\
\hline Rata-rata & 278.562 & 9,57 \\
\hline
\end{tabular}

Sumber: CV. Karunia, 2018

Berdasarkan data di atas, menunjukkan bahwa total volume penjualan kosmetik selama lima tahun terakhir adalah 1.392 .813 dengan tingkat pertumbuhan penjualan rata-rata sebe-sar 9,57 \% setiap tahunnya. Untuk mengantisipasi persaingan yang semakin ketat serta untuk lebih meningkatkan volume penjualan maka upaya yang dilakukan oleh perusahaan adalah dengan menetapkan segmentasi pelang-gan berdasarkan geografis yaitu pengelompok-kan pelanggan menurut daerah pemasarannya. Tujuan perusahaan menerapkan segmentasi pelanggan berdasarkan geografis adalah untuk lebih memfokuskan pemasaran pada suatu wila-yah sehingga perusahaan dapat menetapkan prioritas dalam melayani pelanggan secara maksimal. Wilayah yang ditentukan dalam seg-mentasi pelanggan oleh CV. Karunia Kota Probolinggo, Kabupaten Probolinggo, Dalam upaya untuk menjaga daya saing CV. Karunia, muncul isu menarik yang terangkat dari suatu fenomena yang terjadi di awal milenium bahwa penjualan kosmetik belum sesuai dengan target perusahaan sehingga perusahaan berkeinginan untuk melakukan evaluasi strategi segmentasi pelanggan dalam penjualan kosmetik. Hal inilah yang mendasari penulis untuk mengadakan suatu penelitian dan menganalisisnya guna menjelaskan efektivitas segmentasi pelanggan yang dilakukan oleh perusahaan khususnya dalam 5 (lima) tahun terakhir. Dalam kegiatan penilitian dan penyusunan skripsi ini, penulis memilih judul: "Segmentasi Pelanggan Dengan Metode SOM Sebagai Strategi Pemasaran." Dengan penelitian ini diharapkan proses penjualan di CV. Karunia ini menjadi lebih mudah cepat dan akurat. 


\section{Metode}

Rancangan atau desain penelitian dalam arti sempit dimaknai sebagai suatu proses pengumpulan dan analisis data penelitian. Dibawah ini rancangan penelitian yang dibuat agar pelaksanaan penelitian berjalan dengan baik:

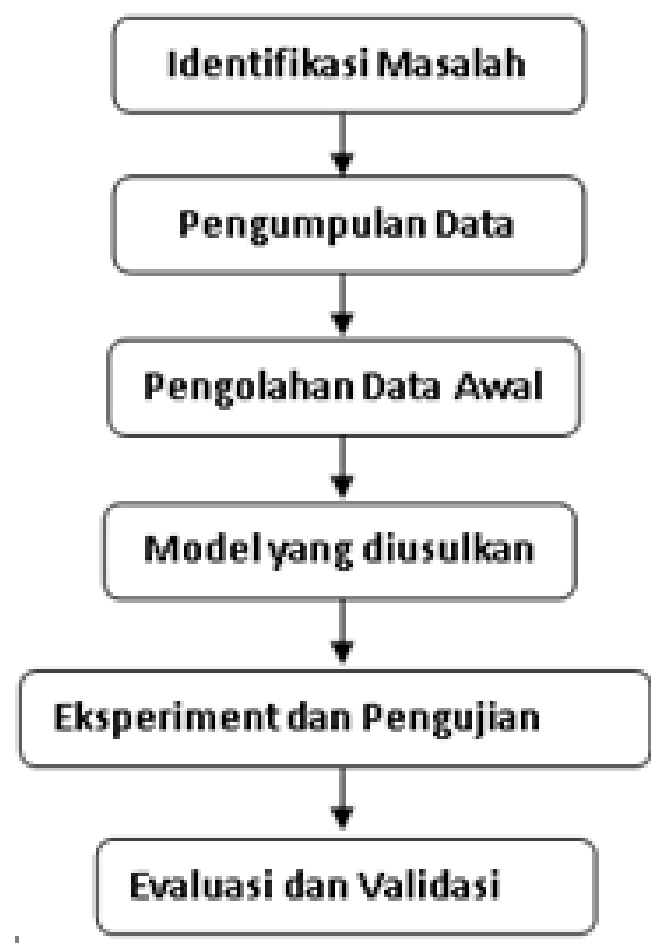

Gambar 1 Rancangan Penelitian

Pada penelitian kali ini yang digunakan adalah penelitian Experiment. Penelitian eksperimen melibatkan penyelidikan perlakuan pada parameter/ variabel tergantung dari penelitinya dan menggunakan tes yang dikendalikan oleh peneliti itu sendiri. Dalam penelitian eksperimen digunakan spesifikasi software dan hardware sebagai alat bantu dalam penelitian pada Tabel 2:

Tabel 2. Spesifikasi Hardware dan Software

\begin{tabular}{|l|l|}
\hline \multicolumn{1}{|c|}{ Software } & Hardware \\
\hline Sistem Operasi : Windows 7 & CPU: Intel Pentium Core i3 \\
\hline Data Mining: Rapid Miner & Memory: 2 GB \\
\hline & Hardisk: 250 GB \\
\hline
\end{tabular}


Pada metode penelitian eksperimen, terdapat beberapa tahapan penelitian yang dilakukan seperti berikut:

\section{Pengumpulan Data}

Pada tahap ini ditentukan data yang akan diproses. Mencari data yang tersedia, mem-peroleh data tambahan yang dibutuhkan, mengintegrasikan semua data kedalam data set, termasuk variabel yang diperlukan dalam proses.

\section{Pengolahan Awal Data}

Ditahap ini dilakukan penyeleksian data, data dibersihkan dan ditransformasikan kebentuk yang diinginkan sehingga dapat dilakukan persiapan dalam pembuatan model.

\section{Model yang diusulkan}

Pada tahap ini data dianalisis, dikelompokan variabel mana yang berhubungan dengan satu sama lainnya. Setelah data dianalisis lalu diterapkan model-model yang sesuai dengan jenis data. Pembagian data kedalam data latihan (training data) dan data uji (testing data) juga diperlukan untuk pembuatan model.

\section{Eksperimen dan Pengujian Model}

Pada tahap ini model yang diusulkan akan diuji untuk melihat hasil berupa rule yang akan dimanfaatkan dalam pengambilan keputusan.

\section{Evaluasi dan Validasi Hasil}

Pada tahap ini dilakukan evaluasi terhadap model yang ditetapkan untuk mengetahui tingkat keakurasian model.

\section{Hasil dan Pembahasan}

\section{Persipan Data}

Data Transaksi Penjualan diperoleh dari CV. Karunia yang bertempat di Probolinggo Jawa Timur. Data ini merupakan data penjualan yang kami dapatkan dari admin CV. Karunia yang berbentuk excel. 
Tabel 3. Tabel Contoh Data Awal

\begin{tabular}{|l|l|l|l|l|}
\hline No & Faktur & Toko & DPP & Nil.Faktur \\
\hline 1 & 16075501 & BC SMKN 1 Probolinggo & 591.724 & 650.897 \\
\hline 2 & 16075502 & Risda Toko, Jln. Mastrip & 238.002 & 261.802 \\
\hline 3 & 16075503 & Dewi Indah, Wonoasih & 53.865 & 59.252 \\
\hline 4 & 16075504 & Ansori H. Toko, Pasar Wonoasih & 132.513 & 145.764 \\
\hline 5 & 16075505 & Stand 08, Pasar Wonoasih & 134.735 & 148.209 \\
\hline 6 & 16075506 & Stand 05, Pasar Wonoasih & 198.570 & 218.427 \\
\hline 7 & 16075507 & Dina, Wonoasih & 812.181 & 893.399 \\
\hline 8 & 16075508 & Dina, Wonoasih & 136.848 & 150.533 \\
\hline 9 & 16075509 & Zaki Toko, Raya Bantaran & 131.652 & 144.817 \\
\hline 10 & 16075510 & Rahayu Toko, Raya Bantaran & 535.966 & 589.562 \\
\hline 11 & 16075511 & Sanur Toko, Kareng Kidul & 609.852 & 670.837 \\
\hline 12 & 16075512 & Aisyah Toko, Raya Kropak & 517.116 & 568.828 \\
\hline 13 & 16075513 & Khotijah Toko, Raya Bantaran & 95.401 & 104.941 \\
\hline 14 & 16075514 & Elfan Toko, JIn. Tempuran & 251.031 & 276.134 \\
\hline 15 & 16075515 & Nyata Abadi Toko, Jl. Mastrip & 593.099 & 652.409 \\
\hline 16 & 16075516 & Indah Jaya, Wonoasih & 164.294 & 180.723 \\
\hline 17 & 16075517 & Sari Rasa Toko, Jln. Wahid & 515.778 & 567.356 \\
\hline 18 & 16075518 & Citra Indah, Jl. Wahid Hasyim & 421.584 & 463.742 \\
\hline 19 & 16075520 & Arip H. Toko, Pasar Bantaran & 35.273 & 38.800 \\
\hline 20 & 16075521 & Antok Toko, Pasar Bantaran & 404.728 & 445.201 \\
\hline
\end{tabular}

\section{Pra Pengolahan Data}

Sebelum langsung dimasukan pada proses pengolahan data, terlebih dahulu dilakukan proses pra pengolahan data diantaranya pembersihan data konversi data dan normalisasi data.

Proses pembersihan data ini dilakukan untuk membuang record yang tidak sesuai dengan kebutuhan contohnya adalah faktur, nama sales, ppn, yang nantikan akan digunakan dalam proses mining, mengendalikan data yang hilang dan melakukan validasi dari 30 setiap record terhadap duplikasi data. Data-data yang tidak konsisten mengandung noise dan banyak kekeliruan membuat hasil pengelompokkan data tidak akurat. 
Tabel 4. Tabel Pembersihan Data

\begin{tabular}{|l|l|l|l|}
\hline No & Tgl & Kd Pelangan & Nil.Faktur \\
\hline 1 & $01 / 05 / 2018$ & Kd0001 & 650.897 \\
\hline 2 & $01 / 05 / 2018$ & Kd0002 & 261.802 \\
\hline 3 & $01 / 05 / 2018$ & Kd0003 & 59.252 \\
\hline 4 & $01 / 05 / 2018$ & Kd0004 & 145.764 \\
\hline 5 & $01 / 05 / 2018$ & Kd0005 & 148.209 \\
\hline 6 & $01 / 05 / 2018$ & Kd0006 & 218.427 \\
\hline 7 & $01 / 05 / 2018$ & $K d 0007$ & 893.399 \\
\hline 8 & $01 / 05 / 2018$ & $K d 0007$ & 150.533 \\
\hline 9 & $01 / 05 / 2018$ & $K d 0008$ & 144.817 \\
\hline 10 & $01 / 05 / 2018$ & $K d 0009$ & 589.562 \\
\hline 11 & $01 / 05 / 2018$ & $K d 0010$ & 670.837 \\
\hline 12 & $01 / 05 / 2018$ & $K d 0011$ & 568.828 \\
\hline 13 & $01 / 05 / 2018$ & $K d 0012$ & 104.941 \\
\hline 14 & $01 / 05 / 2018$ & $K d 0013$ & 276.134 \\
\hline 15 & $01 / 05 / 2018$ & $K d 0014$ & 652.409 \\
\hline 16 & $01 / 05 / 2018$ & $K d 0015$ & 180.723 \\
\hline 17 & $01 / 05 / 2018$ & $K d 0016$ & 567.356 \\
\hline 18 & $01 / 05 / 2018$ & $K d 0017$ & 463.742 \\
\hline 19 & $01 / 05 / 2018$ & $K d 0018$ & 38.800 \\
\hline
\end{tabular}

\section{Penerapan Model RFM}

Pada tahap ini, dilakukan pemilihan atribut yang disesuaikan dengan kebutuhan kriteria model RFM, yaitu rentang waktu transaksi akhir pelanggan dengan periode tertentu, jumlah frekuensi transaksi yang dilakukan pelanggan selama periode yang sudah ditentukan, serta jumlah nominal transaksi untuk setiap pelanggan selama periode tertentu. Berikut uraian mengenai atribut yang dibutuhkan untuk model RFM:

1. Kriteria R (recency) Membutuhkan atribut yang menunjukkan adanya rentang waktu transaksi terakhir pelanggan dengan periode tertentu, sehingga atribut yang dibutuhkan adalah atribut tanggal transaksi.

2. Kriteria F (frequency) Membutuhkan atribut yang merepresentasikan berapa kali pelanggan melakukan transaksi. Kriteria ini ini dapat dilihat dari berapa banyak pelanggan dengan nama yang sama muncul dalam data 
transaksi. Atribut yang dibutuhkan adalah atribut tanggal transaksi yang dihitung jumlahnya.

3. Kriteria M (monetary) Membutuhkan atribut yang berhubungan dengan harga yang telah dihabiskan pelanggan selama melakukan transaksi, sehingga atribut yang dibutuhkan adalah atribut harga total yang harus dibayar pelanggan.

Jika katakanlah perusahaan memiliki sistem pengukuran berskala lima untuk masing-masing dimensi, maka yang bersangkutan dapat memetakan masing-masing pelanggannya berdasarkan data historis yang ada. Contoh skala yang dimaksud adalah sebagai berikut:

Tabel 5. Contoh Sistem Pengukuran Berskala

\begin{tabular}{|l|l|l|l|}
\hline RFM & Skala 3 & Skala 2 & Skala 1 \\
\hline Recency & $1-7$ Hari yang lalu & $8-30$ hari yang lalu & $1-3$ bulan yang lalu \\
Frequenc & 7 x Transaksi keatas & $3 \mathrm{~s} / \mathrm{d} 6 \times$ Transaksi & $1 \mathrm{~s} / \mathrm{d} 3 \mathrm{x}$ \\
$\mathrm{y}$ & & $>=1 . \&<=3 \mathrm{jt}$ & Dibawah $1 \mathrm{jt}$ \\
\hline Monetary & $>=3 \mathrm{jt}$ & \\
\hline
\end{tabular}

Selanjutnya setelah melakukan proses persiapan data dan pra pengolahan data maka selanjutnya adalah pembentukan model RFM agar memudahkan dalam proses pengelompokan data dengan algoritma SOM, dibawah ini hasil dari model RFM yang sudah di bentuk berdasarkan data sebelumnya:

Tabel 6. Data Pelanggan dalam RFM

\begin{tabular}{|l|l|l|l|}
\hline \multicolumn{5}{|c|}{ DATA RFM } \\
\hline Kode & Recency & Frequency & Monetary \\
\hline C730 & 91 & 0 & - \\
\hline 1259 & 91 & 0 & - \\
\hline 2330 & 91 & 0 & - \\
\hline 570 & 91 & 7 & 1.893 .296 \\
\hline 0454 & 91 & 0 & - \\
\hline
\end{tabular}




\begin{tabular}{|c|c|c|c|}
\hline \multicolumn{4}{|c|}{ DATA RFM } \\
\hline Kode & Recency & Frequency & Monetary \\
\hline 5104 & 91 & 0 & - \\
\hline C839 & 91 & 1 & 211.200 \\
\hline 5035 & 91 & 0 & - \\
\hline 7006 & 91 & 0 & - \\
\hline 00201 & 91 & 0 & - \\
\hline 0076 & 91 & 0 & - \\
\hline C998 & 91 & 1 & 302.655 \\
\hline 0142 & 91 & 0 & - \\
\hline 0839 & 91 & 0 & - \\
\hline 0123 & 91 & 0 & - \\
\hline 0841 & 91 & 0 & - \\
\hline 13105 & 91 & 0 & - \\
\hline 1874 & 91 & 0 & - \\
\hline 2660 & 91 & 0 & - \\
\hline 1867 & 91 & 0 & - \\
\hline 2462 & 91 & 0 & - \\
\hline 1622 & 91 & 0 & - \\
\hline 470 & 91 & 0 & - \\
\hline 0118 & 91 & 0 & - \\
\hline 0942 & 91 & 0 & - \\
\hline 0092 & 91 & 0 & - \\
\hline 1180 & 91 & 0 & - \\
\hline 8775 & 91 & 0 & - \\
\hline
\end{tabular}




\begin{tabular}{|l|l|l|l|}
\hline \multicolumn{5}{|c|}{ DATA RFM } \\
\hline Kode & Recency & Frequency & Monetary \\
\hline 2701 & 91 & 1 & 698.927 \\
\hline 2177 & 91 & 0 & - \\
\hline
\end{tabular}

Tabel 7. Tabel RFM yang sudah dikonversi

\begin{tabular}{|c|c|c|c|}
\hline \multicolumn{4}{|c|}{ RFM INTERVAL } \\
\hline NO & Recency & Frequency & Monetary \\
\hline C730 & 1 & 0 & 0 \\
\hline 1259 & 1 & 0 & 0 \\
\hline 2330 & 1 & 0 & 0 \\
\hline 570 & 1 & 3 & 2 \\
\hline 0454 & 1 & 0 & 0 \\
\hline 5104 & 1 & 0 & 0 \\
\hline C839 & 1 & 1 & 1 \\
\hline 5035 & 1 & 0 & 0 \\
\hline 7006 & 1 & 0 & 0 \\
\hline 00201 & 1 & 0 & 0 \\
\hline 0076 & 1 & 0 & 0 \\
\hline C998 & 1 & 1 & 1 \\
\hline 0142 & 1 & 0 & 0 \\
\hline 0839 & 1 & 0 & 0 \\
\hline 0123 & 1 & 0 & 0 \\
\hline
\end{tabular}




\begin{tabular}{|c|c|c|c|}
\hline \multicolumn{4}{|c|}{ RFM INTERVAL } \\
\hline NO & Recency & Frequency & Monetary \\
\hline 0841 & 1 & 0 & 0 \\
\hline 13105 & 1 & 0 & 0 \\
\hline 1874 & 1 & 0 & 0 \\
\hline 2660 & 1 & 0 & 0 \\
\hline 1867 & 1 & 0 & 0 \\
\hline 2462 & 1 & 0 & 0 \\
\hline 1622 & 1 & 0 & 0 \\
\hline 470 & 1 & 0 & 0 \\
\hline 0118 & 1 & 0 & 0 \\
\hline 0942 & 1 & 0 & 0 \\
\hline 0092 & 1 & 0 & 0 \\
\hline 1180 & 1 & 0 & 0 \\
\hline 8775 & 1 & 0 & 0 \\
\hline 2701 & 1 & 1 & 1 \\
\hline 2177 & 1 & 0 & 0 \\
\hline
\end{tabular}

Setelah dilakukan normalisasi data, selanjutnya dilakukan pengelompokan data. Proses pengelompokan (clustering) pada penelitian ini mengunakan cara kerja algoritma SOM dengan untuk clustering dan memvisualisasikan pengelompokan. Pada proses pengelompokan SOM dimulai dengan pembentukan peta jaringan SOM dan pembentukan peta ini didasari dari data in-put yang menjadi masukan terhadap sistem yang dibuat. Kemudian dilakukan proses pembelajaran dengan menggunakan beberapa kali iterasi untuk menghasilkan matrik bobot yang ideal. Matrik bobot ideal inilah yang 
nantinya dipakai untuk memetakan data input tersebut ke dalam kelompok data output. Proses pembelajaran SOM untuk membentuk peta jaringan dikenal dengan nama proses learning. Proses learning ini didasari dari jarak antara data input dengan matrik bobot. adalah parameter yang harus didefinisikan sebelum memulai proses training.

Jaringan SOM yang sudah diinisialisasi kemudian dilakukan proses training. Berikut proses pengelompokan data input menggunakan SOM pada masingmasing parameter.

\section{Pembahasan}

1. Proses Perhitungan Manual Algoritma SOM

a. Akan dilakukan clustering pada 8 buah data contoh

b. Parameter yang digunakan

1) Jumlah cluster 2

2) Jumlah iterasi pelatihan maksimal 6

3) Lajur pembelajaran 0.5

c. Inisialisasi bobot, dengan ukuran matrik dimensi berukuran $2 \times 1$, secara acak digunakan bobot awal sebagai berikut:

$W=\left[\begin{array}{lll}3.02 & 2.1 & 6.99 \\ 1.67 & 2.8 & 6.81\end{array}\right]$

d. Contoh data dari 8 transaksi, dapat dilihat pada tabel di bawah ini.

Tabel 8. Contoh Data dari 8 Transaksi

\begin{tabular}{|l|l|l|l|}
\hline KODE & RECENCY & FREQUENCY & MONETARY \\
\hline 570 & 1 & 3 & 2 \\
\hline C839 & 1 & 1 & 1 \\
\hline C998 & 1 & 1 & 1 \\
\hline 2701 & 1 & 1 & 1 \\
\hline 43 & 1 & 1 & 1 \\
\hline 1833 & 1 & 2 & 3 \\
\hline
\end{tabular}




\begin{tabular}{|l|l|l|l|}
\hline 0040 & 1 & 1 & 1 \\
\hline C507 & 1 & 1 & 1 \\
\hline 1837 & 1 & 3 & 3 \\
\hline
\end{tabular}

Untuk perhitungan manual menggunakan rumus : (Teuvo Kohonen, 1990) $D(J)=\Sigma(W j i-X i)^{\wedge} 2$

Sedangkan untuk update bobot dengan rumus Wji (Baru) $=$ Wji (Lama) $+\alpha(X i-$ Wji (Lama) $)$

$\mathrm{Dj}=$ Jarak Euclidean

$W=$ Bobot Neuron ke-i

$\mathrm{Xi}=$ Input vector $\mathrm{ke} \mathrm{Xi}$

$\alpha=$ Learning Rate

Bobot Awal:

$W=\left[\begin{array}{lll}3.02 & 2.1 & 6.99 \\ 1.67 & 2.8 & 6.81\end{array}\right]$

Iterasi 1 ( kode pelanggan 570 )

Untuk data 1 [ $\left.1 \begin{array}{lll}1 & 3 & 2\end{array}\right]$, hitung jarak setiap neuron :

$\mathrm{D} 1=(3.02-1)^{2}+(2.1-3)^{2}+(6.99-2)^{2}=29.79$

D2 $=(1.67-1)^{2}+(2.8-3)^{2}+(6.88-2)^{2}=24.18$

Jarak terdekat adalah neuron ke-2, maka neuron ke 2 diperbaharui bobotnya :

Update Bobot $=$

W21 $=1,57+0,5 *(1-1,57)=1,29$

W22 $=2,8+0,5 *(3-2,8)=2,9$

W23 $=6,88+0,5 *(2-6,88)=4,44$

Bobot baru setelah diperbaharui :
$W=\left[\begin{array}{ccc}3.02 & 2.1 & 6.99 \\ 1.29 & 2.9 & 4.44\end{array}\right]$ 
Tabel 9. Hasil Data sudah Dicluster

\begin{tabular}{|c|c|c|c|c|c|}
\hline Kode & Recency & Frequency & Monetary & NILAI & Kelas \\
\hline C730 & 1 & 0 & 0 & 1 & Cluster 3 \\
\hline 1259 & 1 & 0 & 0 & 1 & Cluster 3 \\
\hline 2330 & 1 & 0 & 0 & 1 & Cluster 3 \\
\hline 570 & 1 & 3 & 2 & 6 & Cluster 1 \\
\hline 454 & 1 & 0 & 0 & 1 & Cluster 3 \\
\hline 5104 & 1 & 0 & 0 & 1 & Cluster 3 \\
\hline C839 & 1 & 1 & 1 & 3 & Cluster 3 \\
\hline 5035 & 1 & 0 & 0 & 1 & Cluster 3 \\
\hline 7006 & 1 & 0 & 0 & 1 & Cluster 3 \\
\hline 201 & 1 & 0 & 0 & 1 & Cluster 3 \\
\hline 76 & 1 & 0 & 0 & 1 & Cluster 3 \\
\hline C998 & 1 & 1 & 1 & 3 & Cluster 3 \\
\hline 142 & 1 & 0 & 0 & 1 & Cluster 3 \\
\hline 839 & 1 & 0 & 0 & 1 & Cluster 3 \\
\hline 123 & 1 & 0 & 0 & 1 & Cluster 3 \\
\hline 841 & 1 & 0 & 0 & 1 & Cluster 3 \\
\hline 13105 & 1 & 0 & 0 & 1 & Cluster 3 \\
\hline 1874 & 1 & 0 & 0 & 1 & Cluster 3 \\
\hline 2660 & 1 & 0 & 0 & 1 & Cluster 3 \\
\hline 1867 & 1 & 0 & 0 & 1 & Cluster 3 \\
\hline 2462 & 1 & 0 & 0 & 1 & Cluster 3 \\
\hline 1622 & 1 & 0 & 0 & 1 & Cluster 3 \\
\hline 470 & 1 & 0 & 0 & 1 & Cluster 3 \\
\hline
\end{tabular}




\begin{tabular}{|l|l|l|l|l|l|}
\hline 118 & 1 & 0 & 0 & 1 & Cluster 3 \\
\hline 942 & 1 & 0 & 0 & 1 & Cluster 3 \\
\hline 92 & 1 & 0 & 0 & 1 & Cluster 3 \\
\hline 1180 & 1 & 0 & 0 & 1 & Cluster 3 \\
\hline 8775 & 1 & 0 & 0 & 1 & Cluster 3 \\
\hline 2701 & 1 & 1 & 1 & 3 & Cluster 3 \\
\hline 2177 & 1 & 0 & 0 & 1 & Cluster 3 \\
\hline
\end{tabular}

\section{Proses Perhitungan Statistica Trial Algoritma SOM}

\section{a. Proses Clustering}

Proses clustering pada penelitian ini menggunakan Self Organizing Map (SOM) adapun menu yang harus dipilih seperti gambar berikut:

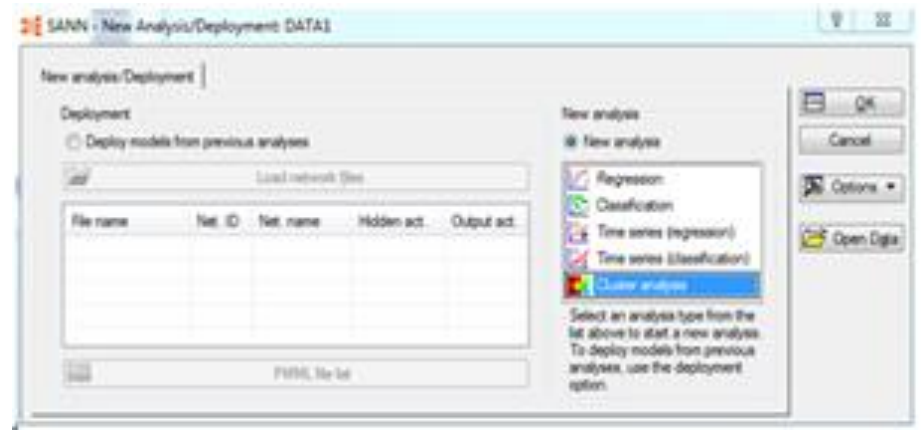

Gambar 2. Tampilan menu analisa clustering

\section{b. Menu Variabel}

Pilih menu variable untuk menentukan variable mana yang akan di lakukan proses clustering:

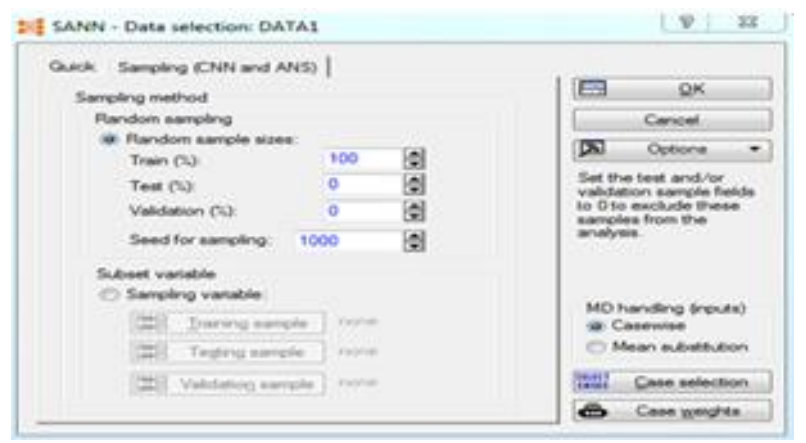


Gambar 3. Tampilan Untuk Menentukan Variable

\section{Menentukan Variabel}

Untuk melakukan proses clustering, variabel yang akan dihitung harus dipilih. Untuk memudahkan menentukan variabel, centang pada check box pada "show oppropriate variable only"

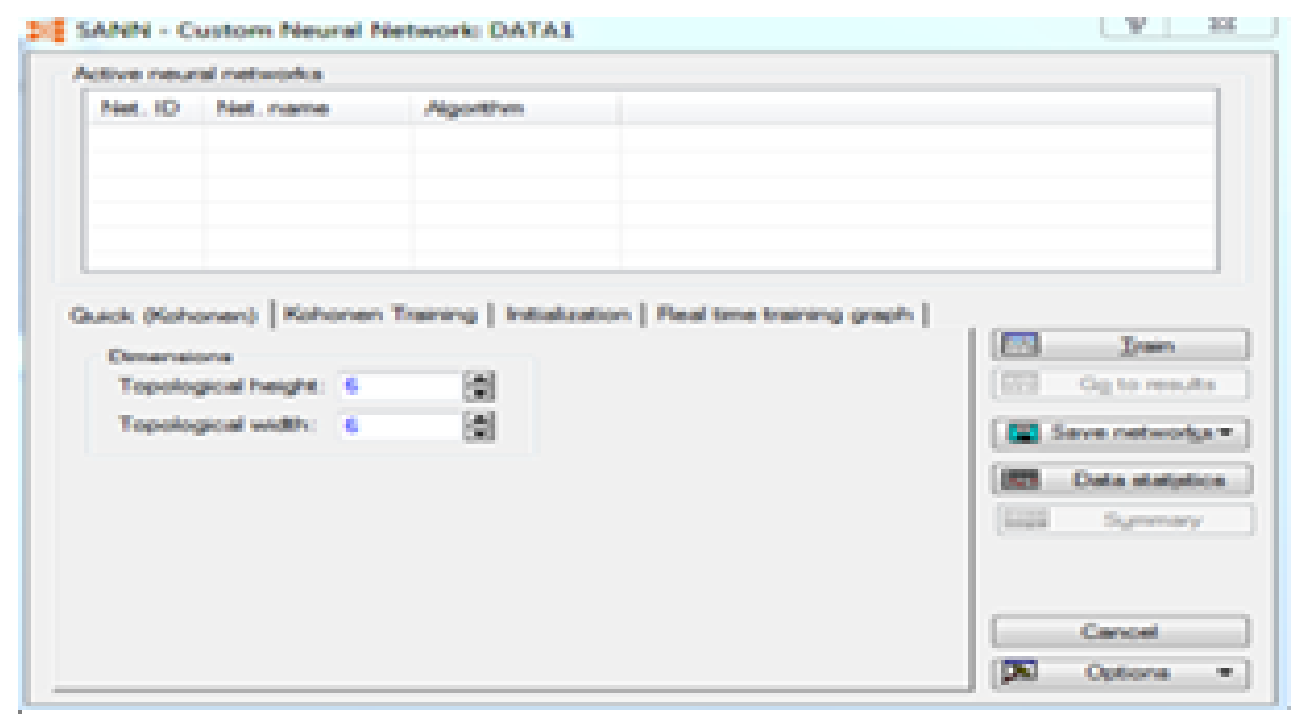

Gambar 4. Penentuan Variabel

\section{Penentuan Sampel Random}

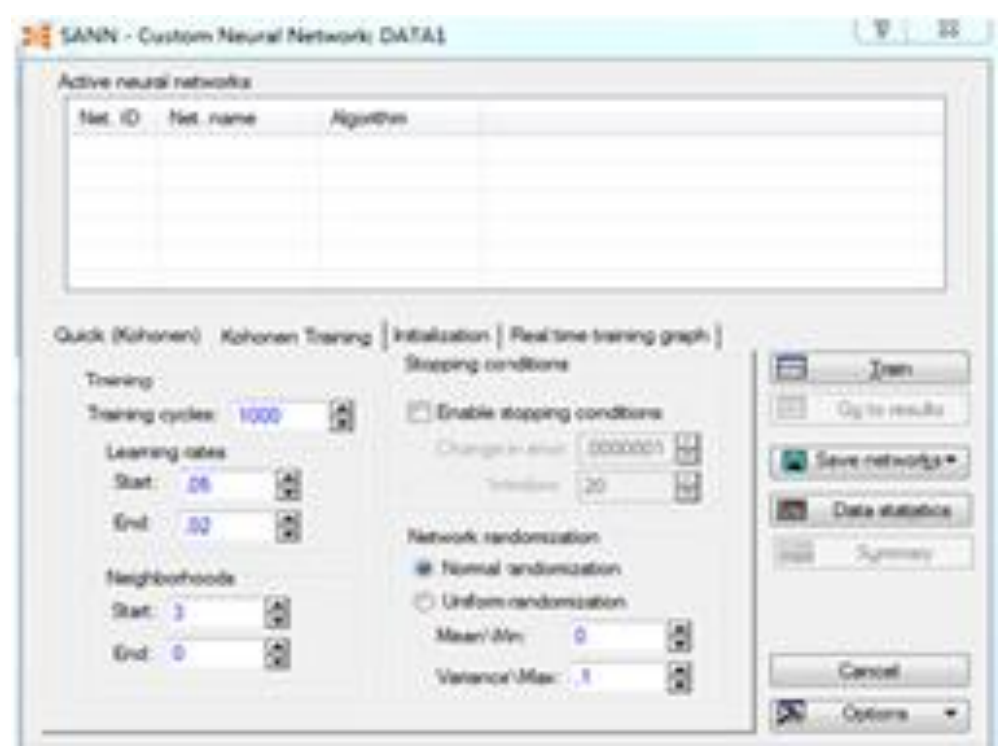

Gambar 5. Menentukan sampel random 


\section{Menentukan Learning Rate, Iterasi}

Learning rate bertujuan sebagai fungsi pembelajaran yang mana untuk memperbaharui bobot baru setian di temukan neuron pemenang dari data yang dihitung. Learning rate untuk pengujian ini dengan nilai yang berkurang dari 0,5 sampai 0,02 dan fungsi ketetanggan yang berkurang dari 3 sampai 0 . Sedangkan iterasi mempunyai fungsi sebagai perulangan untuk menghitung data yang di lakukan. Nilai iterasi di tentukan sebanyak 1000 kali, agar semakin banyak iterasi semakin akurat pengelompokkan yang di hasilkan.

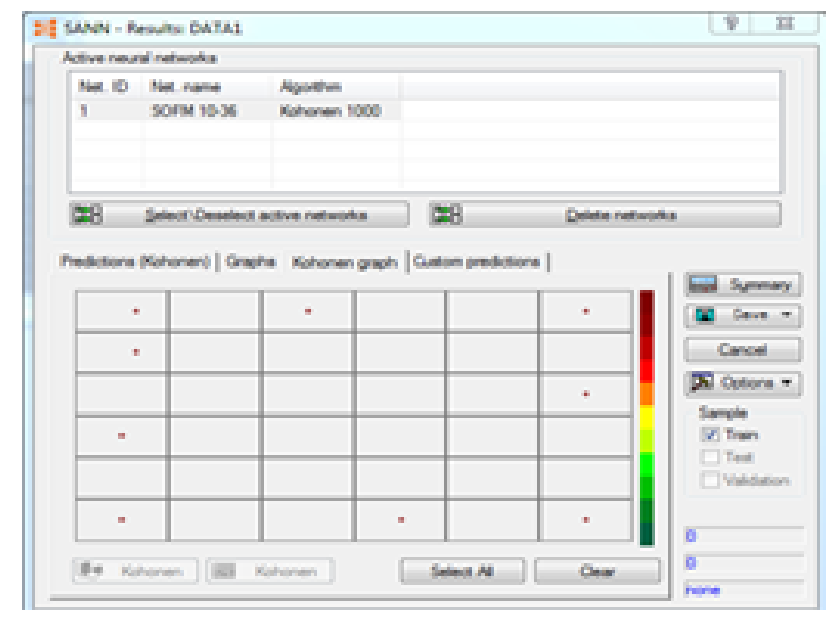

Gambar 6. Hasil cluster

Hasil pengelompokan bias dilihat pada table 4.2, dengan percobaan masukan ukuran dimensi $7 \times 6$ menghasilkan 42 cluster dan untuk cluster $11,19,20,21$ serta 33 tidak memiliki anggota sama sekali yang bearti ukuran dimensi $7 \times 6$ tidak cocok untuk data ini.

\section{Kesimpulan}

Berdasarkan hasil dari implementasi dan pengujian yang dilakukan peneliti, maka dapat ditarik kesimpulan bahwa penelitian ini menghasilkan pemetaan pelanggan dengan metode SOM sebagai strategi pemasaran di CV Karunia. 


\section{Daftar Pustaka}

Ahsan, N. F. (2010). "Clustering Data Mahasiswa menggunakan SOM untuk menentukan Startegi promosi universitas kanjuruhan Malang," IIkom $207,15-17$.

Istiana, M. I. (2016). "Segemntasi Pelanggan Menggunakan Algoritma KMeans Sebagai Strategi Pemasaran pada LAROIBA Seluler," Jurnal 12903, 12-13.

Karomi, M. A. (2016). "Meningkatkan hasil Segmentasi Pelanggan Menggunakan Algoritma Fuzzy C-Means dan Outler Removal Clusstering," STMIK , 2-11. Februari 2007.

Magfirah, A, T. B. (2015). Menggunakan Data Mining Sebagai Customer Pada Bank Untuk Meningkatkan Customer Relationship management (CRM) dengan Metode Klasifikasi (Algoritma J-48, Zero-R dan Naive Bayes). Prosiding SNST, 11.

Saefullah, A, M. (2106). "Penerapan Metode Klasifikasi Data MIning Untuk prediksi Kelulusan Tepat waktu," STMIK jurnal , 14-17. 